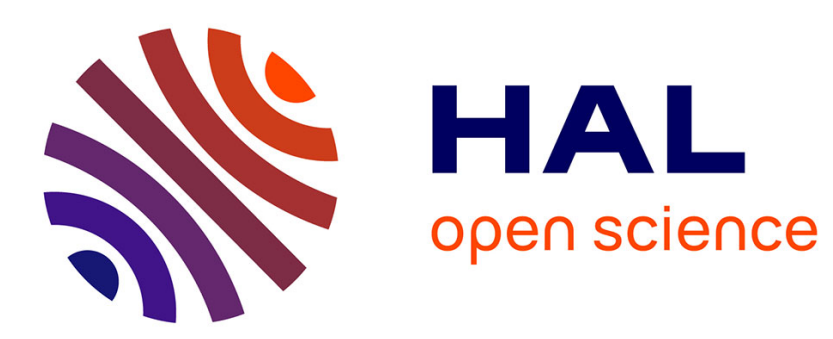

\title{
First observation of a Fano profile following one step autoionization into a double photoionization continuum
}

\author{
L. Journel, B. Rouvellou, D. Cubaynes, J. Bizau, F. Wuilleumier, M. Richter,
} P. Sladeczek, K.-H. Selbmann, P. Zimmermann, Henri Bergeron

\section{- To cite this version:}

L. Journel, B. Rouvellou, D. Cubaynes, J. Bizau, F. Wuilleumier, et al.. First observation of a Fano profile following one step autoionization into a double photoionization continuum. Journal de Physique IV Proceedings, 1993, 03 (C6), pp.C6-217-C6-226. 10.1051/jp4:1993621 • jpa-00251706

\section{HAL Id: jpa-00251706 https://hal.science/jpa-00251706}

Submitted on 1 Jan 1993

HAL is a multi-disciplinary open access archive for the deposit and dissemination of scientific research documents, whether they are published or not. The documents may come from teaching and research institutions in France or abroad, or from public or private research centers.
L'archive ouverte pluridisciplinaire HAL, est destinée au dépôt et à la diffusion de documents scientifiques de niveau recherche, publiés ou non, émanant des établissements d'enseignement et de recherche français ou étrangers, des laboratoires publics ou privés. 


\title{
First observation of a Fano profile following one step autoionization into a double photoionization continuum
}

\author{
L. JOURNEL, B. ROUVELLOU, D. CUBAYNES, J.M. BIZAU, F.J. WULLLEUMIER, \\ M. RICHTER ${ }^{*}$, P. SLADECZEK ${ }^{*}$, K.-H. SELBMANN* ${ }^{*}$ P. ZIMMERMANN* and \\ H. BERGERON**
}

Laboratoire de Spectroscopie Atomique et Ionique, Université Paris Sud, URA 775 du CNRS, B. 350, 91405 Orsay, France

${ }^{*}$ Technische Universität, Berlin, Germany

** LURE, CNRS-CEA-MEN, Université Paris Sud, B. 209d, 91405 Orsay, France

\begin{abstract}
We have measured the double photoionization cross section of sodium atoms between the first $2 s^{2} 2 p^{5} 2 \mathrm{P}$ double photoionization $(52.4 \mathrm{eV})$ and $2 s$-single ${ }^{1.3} \mathrm{~S}$ photoionization thresholds $(71.0 \mathrm{eV})$. We have also observed a Fano profile into the double ionization continuum resulting from the interference between the one-step direct double photoionization process and the resonant double Auger decay of core-excited neutral sodium in the $2 \mathrm{~s} \rightarrow 3 \mathrm{p}$ resonance region. Profiles of absolute partial and total cross sections have been obtained in all important channels. The Fano and Starace parameters, in particular a width of $0.23 \mathrm{eV}$, have been determined, allowing full characterization of the resonance.
\end{abstract}

\section{INTRODUCTION}

Double photoionization in the outer shell of atoms has long attracted considerable interest, because it provides a sensitive test for the importance of electron-electron correlation effects. Early works on the rare gases, $[1-4]$ and on some atomic vapors, [5-8] measured the energy dependence of the branching ratio between double and single photoionization cross sections. They found that double photoionization is not a rare event and provides the material for a critical test of atomic calculations. Many Body Perturbation Theory has been used at that time to calculate double photoionization cross sections.[9, 10] Agreement with the first experimental data available was reasonably good for the simplest rare gases, in particular for helium.[11]

Over the past ten years, the study of double photoionization processes has been extensively developed, owing to the dramatic improvements achieved in the intensity of monochromatic beams of synchrotron radiation (SR) available with newly built dedicated storage rings. Special emphasis was put on two electron processes, including double photoionization. [12-14] In particular, special attention was paid to the threshold[15-23] and high energy [24-27] behaviors of the double photoionization cross section, mostly in the rare gases. More recently, some results have been obtained in the study of energy- and angle-resolved double photoionization, measuring for the first time coincidences between both electrons ejected in the double photoionization processes, in krypton [28] and in helium.[29] Following this intense experimental activity, considerable progress has also been made in the theoretical description of the process, in particular for helium [30, 31] and sodium [32] atoms.

When the primary vacancy occurs in the inner-shell of an atom by photoabsorption of a single photon, doubly charged ions can be produced as the result of two different mechanisms. In the one-step double photoionization process, a second electron is simultaneously ejected from the outer shell via correlation effects.[9]. In the two-step process [12-14, 33], the ejection of the first electron is followed by Auger decay of the singly charged ion. In the double Auger decay, the excess energy is distributed between two electrons that are simultaneously ejected from the singly charged ion, leading to triply charged ions. Experimental evidence for direct double-photoionization processes [34] and for double Auger decay [35, 36] was found many years ago. 
Since 1984, a large number of experimental studies has been performed, dealing mostly with multiple photoionization following inner-shell photoexcitation/ionization in the rare gases [37-51] and in some atomic vapors [52-62]. Electron and mass spectrometries have both been used. In a photoelectron spectrum, a one-step double photoionization process shows up as a structureless continuum, while a twostep double photoionization processes is identified by the observation of discrete lines corresponding to the ejection of electrons with characteristic energy in each step. In an ion spectrum, both one-step and two-step processes produce doubly charged ions. Thus, it is usually not possible to distinguish between one-step and two-step processes in measuring only the relative abundance of singly and doubly charged ions. In addition, the analysis is made more complicated by the possibly remaining excited electron which can act either as an actor or as a spectator in the relaxation of the core-excited state $[46,49,63]$. Moreover, the excited electron can be shaken up to a higher excited orbital [e.g., $4 \mathrm{~d}^{10} 5 \mathrm{~s}^{2} 5 \mathrm{p}^{6}{ }^{1} \mathrm{~S}_{\mathrm{o}} \mathrm{Xe} \rightarrow$ $\left.4 d^{9} 5 s^{2} 5 p^{6} 6 p{ }^{2} P_{1} X e \rightarrow\left(4 d^{10} 5 s^{2} 5 p^{4} 7 p \mathrm{Xe}^{+}+e^{-}\right)\right]$or shaken off into the double photoionization continuum in the so-called resonant double Auger process [e. g. , $4 d^{9} 5 s^{2} 5 p^{6} 6 \mathrm{p} \mathrm{Xe} \rightarrow 4 d^{10} 5 s^{2} 5 p^{4} X^{++}$ $\left.+\mathrm{e}^{-}+\mathrm{e}^{-}\right]$. The competition between these shake-up and shake-off transitions has been qualitatively observed and quantitatively measured $[39,44,46]$. The validity of the spectator model has been questionned by some of the authors and confirmed by other results. Similarly, it has been successively claimed that either the direct one-step route or the indirect two-step route are the dominant processes. The latest results obtained for the rare gases $[44,46]$ establish that shake-up and shake-down processes gain intensity with increasing quantum numbers of the excited electron orbital and that the most important route to doubly-charged ions is via a two-step Auger decay. Since the one-step direct double photoionization cross section was found to be negligible as compared to the resonant double photoionization cross section, no interference effect has been observed and only Lorentzian profiles have been measured in the double photoionization channel.[44]

\section{THE SODIUM CASE}

Alkali-atoms are unique candidates to study multiple ionization processes following inner-shell excitation/ionization, because of their specific electronic structure. Among them, sodium is the most

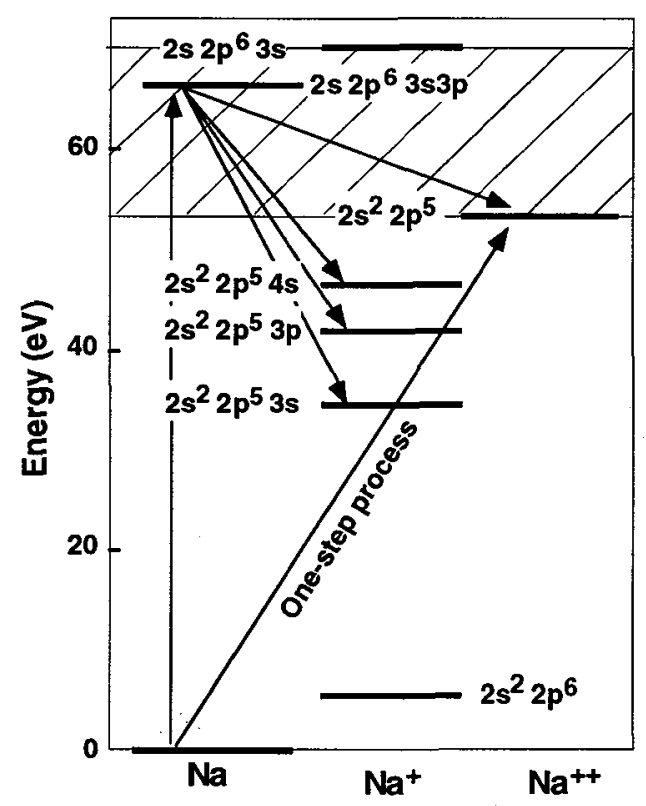

Fig. 1 - Simplified energy level diagram of neutral, singly-, and doubly-charged atomic sodium. The energy scale refers to the ground state of neutral sodium. The energy region investigated in this work extends from the $2 s^{2} 2 p^{5}{ }^{2} P_{1 / 2,3 / 2}$ double ionization thresholds, at $52.4 \mathrm{eV}$, up to the $2 \mathrm{~s}_{2} \mathrm{p}^{6} 3 \mathrm{~s}{ }^{1,3} \mathrm{~S}$ single ionization thresholds at $71.0 \mathrm{eV}$ [64], respectively. favorable case, owing to various theoretical and experimental considerations. The energy level diagrams of $\mathrm{Na}, \mathrm{Na}^{+}$and $\mathrm{Na}^{++}$are schematically shown in Figure 1 , up to $71 \mathrm{eV}$ energy above the ground state. Single ionization of neutral sodium in the $3 \mathrm{~s}-, 2 \mathrm{p}-$, and $2 \mathrm{~s}-$ subshells requires $5.14 \mathrm{eV}, 38.0 \mathrm{eV}$, and $71.0 \mathrm{eV}$, respectively. The first double ionization threshold, involving simultaneous removal of the outer shell $3 \mathrm{~s}$ and first inner-shell $2 \mathrm{p}$ electrons occurs at $52.4 \mathrm{eV}$, according to: $2 s^{2} 2 \mathrm{p}^{6} 3 \mathrm{~s}^{2} \mathrm{~S}+\mathrm{hv} \rightarrow 2 \mathrm{~s}^{2} 2 \mathrm{p}^{5} 2 \mathrm{P}+\mathrm{e}^{-}+\mathrm{e}^{-}$. This means that, between $52.4 \mathrm{eV}$ and $71.0 \mathrm{eV}$ energy, the two-step Auger route cannot occur. Thus, only one-step double photoionization involving the simultaneous ionization of a $2 \mathrm{p}$-inner electron and of the outer electron can produce doubly charged ions in this energy range. At $66.6 \mathrm{eV}$ and above, there are discrete core-excited states forming Rydberg series converging to the $2 \mathrm{~s}$-ionization thresholds $\left(2 \mathrm{~s} 2 \mathrm{p}^{6} 3 \mathrm{~s} 1,3 \mathrm{~S}\right.$ at $71.0 \mathrm{eV}$ [64]). These autoionizing states are accessible by photoexcitation of a 2 s-electron according to: $2 s^{2} 2 \mathrm{p}^{6} 3 s^{2} \mathrm{~S}+\mathrm{hv} \rightarrow 2 \mathrm{~s}^{2} \mathrm{p}^{6} 3 \mathrm{snp}{ }^{2} \mathrm{P}$. Earlier photoabsorption measurements, [65] have observed and identified the first members of the series. These excited states lie above the first $2 s^{2} 2 p^{5}{ }^{2} P_{1 / 2,3 / 2}$ doubleionization thresholds, but below the next inner-shell single ionization and the second double ionization $\left(2 s^{2} 2 p^{4} 3 s\right.$, around $\left.100 \mathrm{eV}\right)$ thresholds.

In the work presented here, we have measured the relative abundance of $\mathrm{Na}^{+}$and $\mathrm{Na}^{++}$ions produced between $52.4 \mathrm{eV}$ and $71 \mathrm{eV}$ photon energy. At $66.6 \mathrm{eV}$, the excited $2 s 2 p^{6} 3 s\left({ }^{3} S\right) 3 p$ $2 \mathrm{P}$ state decays preferentially by autoionization. One of the possible decay route is to the $2 s^{2} 2 p^{5} 2 \mathrm{p}$ doubly ionized states. At this photon energy, the direct one-step double photoionization can 
interfer on resonance with the resonant double Auger process (also called resonant double autoionization). All other relaxation schemes lead to singly charged final states of $\mathrm{Na}^{+}$ions. In Figure 1 , we have represented three of them that can also be reached by direct photoionization from the ground state of atomic sodium: $2 s^{2} 2 p^{5} 3 s$ 1,3 , with only one $2 p$-electron being removed, corresponding to the "main line" in a photoelectron spectrum; $2 s^{2} 2 p^{5} 3 p{ }^{2} \mathrm{P}$ with the outer 3s-electron being simultaneously excited onto a 3p-orbital via continuum state interaction (the excited electron has changed its orbital quantum number by one unit), corresponding to the so-called "conjugate shake up" satellites (CSU); and the $2 s^{2} 2 p^{5} 4 s^{1,3}$ states, with the $3 s$-outer electron being simultaneously excited onto a $4 \mathrm{~s}$-orbital via a monopole transition (the excited electron does not change its orbital quantum number), corresponding to shake up satellites (SU). In a previous work, [66] photoelectron spectra of sodium have been recorded at many photon energies in the same photon energy range, showing strong variations of the relative intensity of some of the photoelectron lines in the energy region of the resonance. Using these previous data and the newly obtained results, we have been able to determine absolute values of the partial photoionization cross sections by normalization to the absolute photoabsorption cross section, to determine the Fano parameters of the resonance in the total photoabsorption cross section [67, 68], and to analyze with the Starace's formulation [69] the line profiles in the different ionization channels, in particular in the double photoionization channel that shows a characteristic Fano profile.

\section{EXPERIMENT}

SR from the BESSY storage ring was used between $50 \mathrm{eV}$ and $71 \mathrm{eV}$ to analyze the ratio of $\mathrm{Na}^{++}$and $\mathrm{Na}^{+}$ions produced by photoionization. A schematic view of the experimental set up is shown in Figure 2. The light emitted from a bending magnet of BESSY was monochromatized by a toroidal grating monochromator (TGM) with a relative resolution $\Delta \mathrm{hv} / \mathrm{hv}=4 \times 10^{-3}$. Closing the TGM slits to a width of $300 \mu \mathrm{m}$ and using a 950 lines/mm grating, the photon flux was $\cong 4 \times 10^{10}$ photons/second in a band pass of $0.3 \mathrm{eV}$ at $65 \mathrm{eV}$ photon energy and for $100 \mathrm{~mA}$ electron current in the ring. To suppress higher order contributions to the monochromatized light, we mounted an aluminum foil of $100 \mathrm{~nm}$ thickness into the beam. The monochromatized light was focused into the interaction zone of a time-of-flight-ion-mass analyzer (TOF) where it crossed a heam of $\mathrm{Na}$ atoms generated inside a resistively heated furnace. Ions produced by photoionization were extracted and accelerated into the drift section of the TOF by electrostatic pulses of $300 \mathrm{~V}$ amplitude, a pulse length of typically $2 \mu \mathrm{s}$ and a pulse frequency of $25 \mathrm{kHz}$. Measuring the time of flight of the ions between interaction zone and detector, a separation in regard to the ratio of mass and charge was possible.

A typical TOF ion spectrum, measured at $60 \mathrm{eV}$ photon energy, is shown in Figure 3 Numerous ionic lines appear, partly due to photoionization of the residual molecular gases by SR. However, the most intense signal is the $\mathrm{Na}^{+}$ion line around channel number 2500 . Near channel number 1700 , one observes also a very small signal that can be identified as a $\mathrm{Na}^{++}$ion line produced by direct double photoionization of $\mathrm{Na}$ atoms.

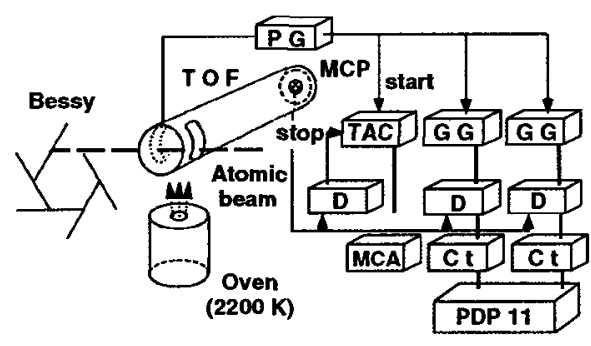

Fig. 2- Scheme of the experimental set up used for the photoion spectrometry measurements described in this work (see text for detailed explanation).

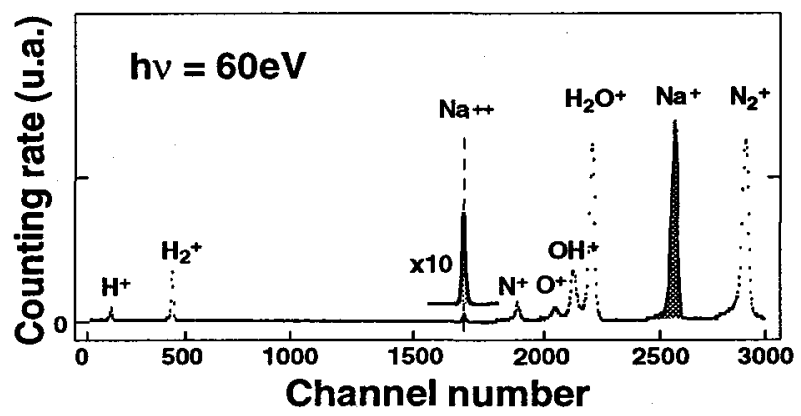

Fig. 3 - A time-of-flight (TOF) ion spectrum measured at $60 \mathrm{eV}$ photon energy. Ionic lines are due to photoionization of the residual gas, and to single and double photoionization of atomic sodium.

For a large number of photon energies, the ratio of $\mathrm{Na}^{++}$and $\mathrm{Na}^{+}$intensities was measured from spectra similar to the one shown in Figure 3. After that proper instrumental corrections, mainly for the ion detector efficiency, have been applied, the relative cross section for formation of $\mathrm{Na}^{++}$ions was obtained as a function of photon energy. The detailed experimental procedure will be given elsewhere. [70] 


\section{RESULTS}

Figure 4 presents the relative cross section for double photoionization of atomic sodium as a function of photon energy between the double ionization threshold and the single $2 \mathrm{~s}$-inner shell ionization thresholds. The data points have been extracted from the $\mathrm{Na}^{++} / \mathrm{Na}^{+}$ratios measured at different photon energies. As expected, no $\mathrm{Na}^{++}$signal was observed below $52.4 \mathrm{eV}$ and the double photoionization cross section starts

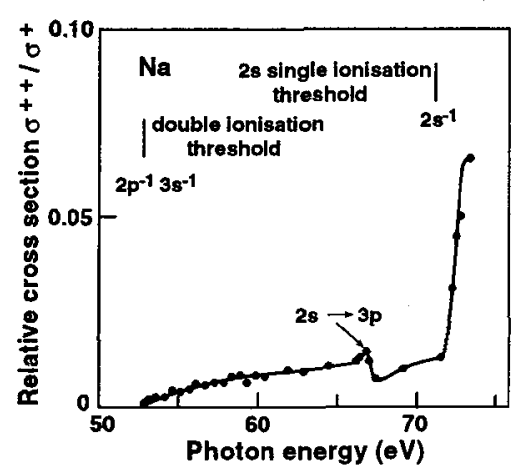

Fig. 4- Variation, as a function of photon energy between the first double photoionization threshold and the 2 s-single photoionization threshold, of the $\mathrm{Na}^{++} / \mathrm{Na}^{+}$ branching ratio measured in this work.

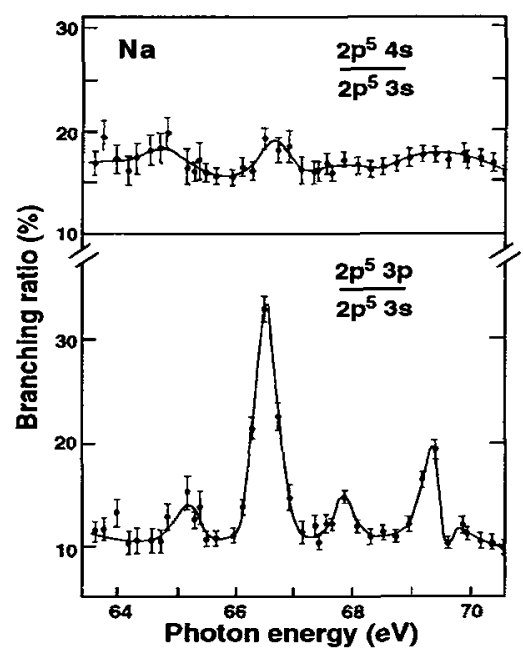

Fig. 5 - Variation of the branching ratio between the shake up (top) or conjugate shake up (bottom) satellite (photoionization + excitation) intensities and the main line (single photoionization) intensity in the $2 \mathrm{~s} \rightarrow$ np resonance region in sodium. The measurements have been made using photoelectron spectrometry (from Cubaynes et al., Ref. [66]).

Branching ratios into the different final state channels is an interesting parameter to know. However, a true comparison of relative intensities and profiles can be made only on the energy dependence of the absolute partial photoionization cross sections. This will be the subject of the next paragraph. direct double photoionization (shake off) contributes to the production of $\mathrm{Na}^{++}$ions outside of the $2 s \rightarrow \mathrm{np}$ resonance energies, the cross section between $52.4 \mathrm{eV}$ and $71.0 \mathrm{eV}$ for the $2 s^{2} 2 p^{6} 3 s+h v \rightarrow 2 s^{2} 2 p^{5}+e^{-}+e^{-}$shake off process can be read directly from Figure 4 to increase from 0 to about $1 \%$ of the total single photoionization cross section. The sudden increase in the $\mathrm{Na}^{++}$ion formation at $71.0 \mathrm{eV}$ was also expected, since normal Auger decay of a $2 \mathrm{~s}$-vacancy ends up in the $\mathrm{Na}^{++}$ground state.

Let's turn now to the apparently weak Fano-type structure at 66.6 $\mathrm{eV}$, indicating a strong coupling of the shake off process to the corresponding $2 s \rightarrow 3 \mathrm{p}$ resonance. First of all, since the resonant state is an excited state of the neutral atom, only the double resonant Auger process can contribute to the decay of this excited state into the doubly ionized $2 s^{2} 2 p^{5}{ }^{2} P_{1 / 2,3 / 2}$ final states. In addition, this process seems to interfer with the direct one-step double photoionization, suggesting that the intensity of both processes are in the same order of magnitude. In previous work dealing with decays of core-excited resonances, the direct shake off process was negligible compared to the resonant process, precluding the observation of any Fano-type profile similar to the one observed here. In order to establish a valuable comparison with the effect of the resonance into the singly ionized channels, we recall in Figure 5 an example of the results that have been previously obtained using photoelectron spectrometry for two of the singly ionized final states of $\mathrm{Na}^{+}$in the same energy region [66]. The branching ratios shown in this figure were determined by measuring a large number of photoelectron spectra in the photon energy range of interest, i.e., the CIS (constant ionic state) method was not used. Variations of the incident photon flux were monitored by measuring the integrated area under the 2p-photoelectron line of neon atoms simultaneously introduced in the source volume of the cylindrical mirror analyzer used to energy analyze the photoelectrons (CMA). [66] The variation of the Na atoms density as a function of time was also systematically checked by measuring periodically the same photoelectron spectrum at a given photon energy. Possible changes of this density were accounted for. In the upper part of the figure, one sees the branching ratio for the shake up satellite intensity $\left(2 s^{2} 2 p^{5} 4 s / 2 s^{2} 2 p^{5} 3 s\right)$, and, in the lower part, the branching ratio for the first conjugate shake up satellites $\left(2 s^{2} 2 p^{5} 3 p / 2 s^{2} 2 p^{5} 3 s\right)$. The branching ratio is apparently enhanced on resonance by a factor 2.8 in the CSU channel and by a factor 1.5 in the double ionization channel. One does not observe a strong effect in the SU channel. In Table I, we have summarized the values of the branching ratios measured off and on resonance in all observed channels, including the single ionization channel. Note that every feature observed in photoabsorption measurements [65] is also observed here, especially in the CSU branching ratio. The second resonance of the series, $2 s \rightarrow 4 p$, at $69.3 \mathrm{eV}$ photon energy, has also some effect in this channel. from zero at threshold. Since, between $52.4 \mathrm{eV}$ and $71.0 \mathrm{eV}$, only 
Table I. Branching ratios for photoionization of $\mathrm{Na}$ into the various final state channels off resonance and at $66.6 \mathrm{eV}$ resonance energy $\left(2 \mathrm{p}^{5} 3 \mathrm{~s}\right.$ channel $\left.=100\right)$.

$\begin{array}{lccc}\text { Final state } & \text { Off resonance } & \text { On resonance } & \text { Enhancement factor } \\ 2 s^{2} 2 p^{5} 3 p & 12 & 33 & 2.8 \\ 2 s^{2} 2 p^{5} 4 s & 16 & 19 & 1.2 \\ 2 s^{2} 2 p^{5} 4 p & 2 & 5 & 2.5\end{array}$

\section{DISCUSSION}

We have established all partial cross sections on the same relative scale using photoion and photoelectron spectrometries. Then, we determined the absolute scale of the cross sections by normalizing, at $64 \mathrm{eV}$ photon energy, $i$. e., on the low energy side of the $2 s \rightarrow 3 p$ resonance, the relative cross sections to the absolute photoabsorption cross section as measured by Codling et al.[71]. This is possible only when all

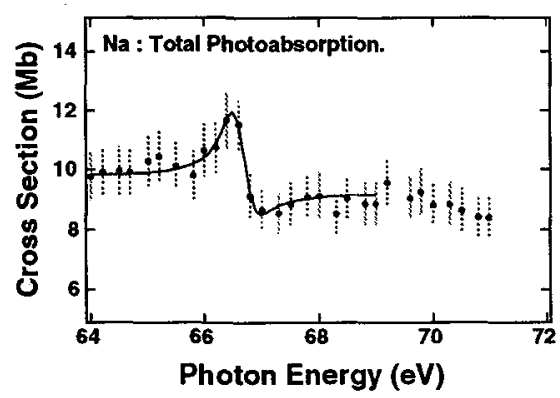

Fig. 6- Total photoabsorption cross section of sodium. This result has been obtained in adding the partial contributions into the different photoionization channels as determined using photoelectron and photoion spectrometries. photoionization channels have been previously analyzed.

Let's discuss first the total photoabsorption curve in the energy region of the $2 s \rightarrow 3 p$ resonance obtained by adding the contributions of our partial cross sections determined into the different ionization channels. The resulting curve is shown in Figure 6 as points with error bars. The error bars take into account the errors in determining the branching ratios, including corrections due to variation of the photon flux and possible changes in the atomic density. Like for all data presented in this paper, the overall uncertainty on the absolute value of the total photoabsorption cross section used for normalization is not included. Absolute values of the partial cross sections would of course be affected if the normalization point would change, but not the shape neither the parameters of the partial cross sections in the region of the resonance. Note that the values of the cross section on the low energy side of the resonance are $15 \%$ to $20 \%$ higher, in comparison to the value of the cross section at the top of the $2 \mathrm{~s} \rightarrow 3 \mathrm{p}$ resonance, than in the data of Wolff et al.[65]. In fact, these authors have measured only the relative shape of the absorption spectrum. The fact that the $2 \mathrm{~s} \rightarrow 3 \mathrm{p}$ resonance appears with a better contrast in the measured photoabsorption curve than in the reconstructed curve might be attributed to the better resolution of the photoabsorption data, $\cong 0.01 \mathrm{~nm}$ against about $0.03 \mathrm{~nm}$ in our work.

\subsection{Fano parameters for the total photoabsorption cross section.}

According to Fano, $[67,68]$ the total photoabsorption cross section $\sigma_{\text {tot }}$ for the case of an isolated resonance interacting with several continua states can be parametrized in the following form:

$$
\begin{array}{ll} 
& \sigma_{\text {tot }}(E)=\sigma_{0}(E)\left[\rho^{2}(q+\varepsilon)^{2} /\left(1+\varepsilon^{2}\right)+1-\rho^{2}\right] \\
\text { with: } \quad & \varepsilon=\left(E-E_{0}\right) / \Gamma / 2
\end{array}
$$

where the Fano parameters $q$ (profile index) and $\rho^{2}$ (correlation coefficient) are assumed to be constant over the resonance, $\sigma_{0}$ (E) gives the nonresonant cross section, $\Gamma$ and $E_{0}$ are the width and the energy of the resonance, respectively. $q$ and $\rho$ can be expressed as a function of the wavefunction of the ground and final states.[67, 68]

In order to extract the true resonance parameters from the experimental data, a deconvolution of the experimental photoabsorption cross section with the monochromator band pass function must be performed. However, rather than using such a deconvolution, the true resonance profile (generated from the parameters $\mathrm{E}_{\mathrm{O}}, \Gamma, \mathrm{q}$ and $\rho^{2}$ ) was convoluted with the monochromator band pass function (a Gaussian 
profile with $0.31 \mathrm{eV}$ FWHM) and then compared with the experimental data by a least-squares fit. For this purpose, a linear behavior of the nonresonant cross section $\sigma_{0}$ was assumed and none of the parameters was a priori kept fixed. Starting values to inject into the fitting procedure were extracted directly from the experimental data. The procedure was repeated systematically, the $\chi^{2}$ values providing Table II. Fano parameters for the $2 s \rightarrow 3$ p resonance in sodium

$\begin{array}{lcccc}\text { Eo }(\mathrm{eV}) & \Gamma(\mathrm{eV}) & \mathrm{q} & \rho^{2} & \sigma_{\mathrm{o}}(\mathrm{Mb}) \\ 66.64(2) & 0.23(1) & -1.73(4) & 0.13(1) & 9.6(6)\end{array}$
the criterion to select the best set of resonance parameters. Table II lists the final values of the resonance parameters determined in that way, using Mathematica software.

Codling et al. [71] have estimated a $q-$ value of $-2( \pm 0.5)$, in agreement with previous estimations by Wolff et al.[64] Our determination is more accurate, and confirms the validity of the first estimations. The width of the resonance $\Gamma, 0.23 \mathrm{eV}$, is significantly smaller than previously estimated by Codling et al. on the basis of a $q$-value of -2 . It is interesting to compare our value with a completely independent determination of the widths of the transitions: $2 s^{2} p^{6} 3 s{ }^{1,3} s \rightarrow 2 s^{2} 2 p^{5}{ }^{2} P_{1 / 2}, 3 / 2$ in Na by Breuckman et a1.[72]. Studying the Auger spectrum of $\mathrm{Na}$ produced by electron impact excitation, they measured, for both ${ }^{1,3} \mathrm{~S} \rightarrow{ }^{2} \mathrm{P}$ transitions, widths of 0.24 (2) $\mathrm{eV}$, in excellent agreement with our determination since the widths of these different transitions is mainly governed by the natural width of the $2 \mathrm{~s}$-hole.

Our value of $0.23 \mathrm{eV}$ for the width of the $2 \mathrm{~s} 2 \mathrm{p}^{6} 3 \mathrm{~s} 3 \mathrm{p} 2 \mathrm{P}$ state is equivalent to an autoionization lifetime of $2.9 \times 10^{-15} \mathrm{sec}$, i. e., about twenty times less than that of the $2 \mathrm{~s} 2 \mathrm{p}^{6} 3 \mathrm{p}$ state in Ne measured long time ago by Madden and Codling.[73] This is qualitatively understandable since, in the case of neon, only one channel, the $2 s^{2} 2 p^{5}{ }^{2} P_{1 / 2}, 3 / 2$ channel, is accessible to autoionization, while many more channels, including the double photolonization channel, are open in the case of the $2 s 2 p^{6} 3 s^{3} p^{3} p$ state in sodium.

The oscillator strength $f$ of the $2 s \rightarrow 3 p$ transition can also be deduced from our experimental measurements, since it is related to the Fano parameters by the expression:

$$
\mathrm{g} f=0.195 \mathrm{q} 2 \rho^{2} \sigma_{\mathrm{t}} \Gamma
$$

where $\mathrm{g}$ is the statistical weight $2 \mathrm{~J}+1, \sigma_{\mathrm{t}}$ is expressed in megabarns, $\Gamma$ is measured in Rydbergs. With the values given in Table $\Pi$, we obtain $f=1.7(2) \times 10^{-3}$, a value almost identical to the oscillator strength of the $2 \mathrm{~s} \rightarrow 3 \mathrm{p}$ transition in neon similarly determined.[73] This equality confirms once more that correlation effects between the core and the outer electrons in sodium have little influence on the innershell photoexcitation spectra.

\section{2 Partial cross sections}

Absolute values of the partial cross sections were determined using the same normalization as for the total photoabsorption cross section. They are shown in Figure 7 for the three most important continuum channels studied in this work, i. e., from top to bottom, the CSU channel, the double ionization channel and the single $2 \mathrm{p}^{-1}$ photoionization channel. Note the quite different ordinate scales for each of the three pannels. The experimental values are the points with error bars. The overall error on the total photoabsorption cross section used for normalization, $20 \%$ to $25 \%$, is not included in the values of the partial cross sections. Interestingly enough, strongly different profiles appear on resonance in the various continua. In the CSU channel, the cross section has an almost lorentzian profile, as it was already evident in the figure showing the branching ratios, confirming that little interference occurs between the weak direct process and the strong indirect resonant process. This is not the case in the single $2 \mathrm{p}^{-1}$, and, even more, in the double photoionization channels where one observes two similar Beutler-Fano profiles, although the absolute values of the cross sections are strongly different in both continua. Since the first observations in single photoionization of helium [74], many Fano profiles have been observed [14, 75$78]$ in single photoionization channels, but it is the first time, to our knowledge, that such a profile is directly observed following a one-step decay of a neutral core-excited state into a double photoionization continuum. Related measurements are the recent observations of Auger transitions contributing to valence double photoionization [79], and of asymmetric photoelectron line profiles [80, 81] in inner-shell shake up satellites lying above the double ionization threshold involving less bound electrons, suggesting a coupling between discrete satellite states with underlying shake off continua.

In Figure 7, the solid lines are the result of a fitting of the experimental data to theoretical formulations including several parameters. Theoretical expressions for the behavior of partial cross sections within a resonance have been formulated by Starace [69], in a form analogous to the Fano formula describing the behavior of the total cross section in the neighborhood of an isolated resonance. The expression for the partial cross section in the observable photoemission channel $\mu$ at energy $E$ is given, as a function of the 
Fano q parameter and the real and imaginary parts of a new parameter $\alpha(\mu, \mathrm{E})$, according to:

$$
\text { with: } \quad \begin{aligned}
& \sigma(\varepsilon)=\sigma_{\mathrm{o}}(\varepsilon) \frac{\mathrm{C}_{1}+\mathrm{C}_{2} \varepsilon+\varepsilon^{2}}{1+\varepsilon^{2}} \\
& \mathrm{C}_{1}(\mu, \varepsilon)=2\left[\mathrm{q} \operatorname{Re}<\alpha_{\mu}>-\operatorname{Im}<\alpha_{\mu}>\right] \\
& \mathrm{C}_{2}(\mu, \varepsilon)=1-2 \mathrm{q} \operatorname{Im}<\alpha_{\mu}>-2 \operatorname{Re}<\alpha_{\mu}>+\left(1+\mathrm{q}^{2}\right)\left|\alpha_{\mu}\right|^{2}
\end{aligned}
$$

$\sigma_{\mathrm{o}}(\varepsilon)$ is a slowly varying nonresonant partial cross section. The complex parameters $\alpha_{\mu}$ are given by:

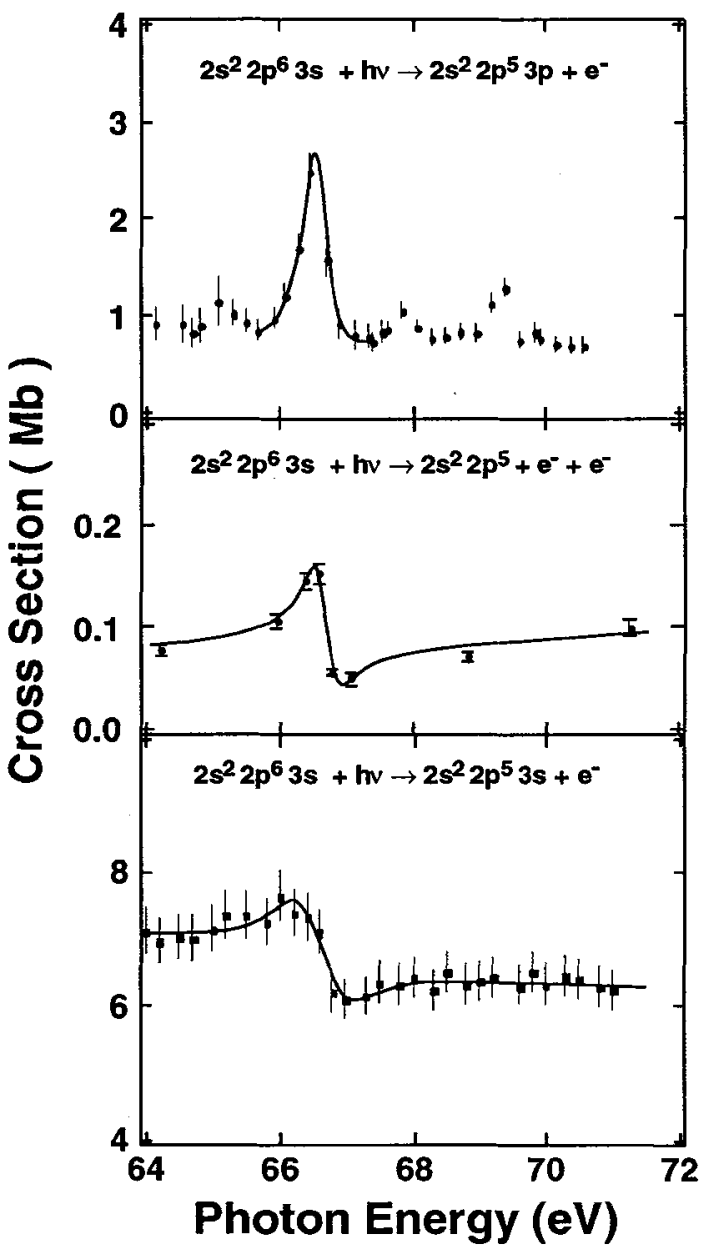

Fig. 7 - Partial photoionization cross sections for photoionization of atomic sodium into the CSU-, double- and single $2 \mathrm{p}^{-1}$ photoionization channels, respectively (from top to bottom). where $g$ represents the ground state, $\Phi$ is the final state, mixing discrete and continuum states, and V is the Coulomb interaction. The summation extends over all photoionization channels $\mu$.

In Figure 7, the solid curves represent leastsquares fit to the function $\sigma(\varepsilon)$ convoluted with the instrumental function describing the monochromator band pass. The same procedure was used as for the determination of $\mathrm{q}$ and $\Gamma$ from the total photoabsorption cross section. All parameters, including $\Gamma$, were again treated as free parameters. The numerical results of the least-squares fit for each photoionization channel are given in Table III. The $\Gamma$ values deduced from the partial cross section measurements are equal to the one determined from the total photoabsorption cross section.

The single $2 \mathrm{p}^{-1}$ and double $2 \mathrm{p}^{-1} 3 \mathrm{~s}^{-1}$ partial cross sections have similar profiles, although their absolute values are widely different, by nearly a factor 70 off resonance, the intensity in the double photoionization continuum showing a larger fractional rise (1.5) than does the intensity in the single $2 \mathrm{p}^{-1}$ photoionization channel (1.2). The CSU profile is slightly higher on the low energy side, but a symmetric Lorentzian curve will fit into within the experimental error. It has the largest fractional rise on resonance (2.8). The actual value is, in fact higher $(\cong 4.5)$ because of instrumental broadening. The total cross section which receives about $70 \%$ of its intensity from the single ionization channel has a shape similar to the single photoionization cross section. 
Table III. Fitting parameters for the partial cross sections

$\begin{array}{llccc}\text { Ionic state } & \Gamma(\mathrm{eV}) & \mathrm{C}_{1} & \mathrm{C}_{2} & \sigma_{\mathrm{o}}(\mathrm{Mb}) \\ 2 \mathrm{~s}^{2} 2 \mathrm{p}^{5} 3 \mathrm{~s} & 0.23(1) & 1.10(5) & -0.50(5) & 7.2(4) \\ 2 \mathrm{~s}^{2} 2 \mathrm{p}^{5} 3 \mathrm{p} & 0.230(5) & 4.50(5) & -1.00(5) & 0.84(5) \\ 2 \mathrm{~s}^{2} 2 \mathrm{p}^{5} & 0.230(5) & 1.69(1) & -1.84(1) & 0.082(5)\end{array}$

\section{CONCLUSION}

The use of both photoelectron and photoion spectrometries has been demonstrated to be necessary to characterize an isolated resonance interacting with several continua.The total photoabsorption and partial photoionization cross sections have been fully parametrized. The width of the $2 s^{2} 2 p^{6} 3 s^{2} S \rightarrow 2 s^{2} 2 p^{6} 3 s^{3} p$ 2P resonance in $\mathrm{Na}$ has been accurately measured. The high sensitivity of ionic detection has provided the first direct observation of a Fano profile in a double photoionization continuum following one step autoionization, in spite of the weak strength associated with this channel, thirty years after the first observation of such a profile in the $\mathrm{He}^{+}$singly ionized channel

\section{REFERENCES}

[1] Carlson T. A., Phys. Rev. 156 (1967) 142-149.

[2] Wight G. R. and Van der Wiel M. J., J. Phys. B 9 (1976) 1319-1327.

[3] Schmidt V., Sandner N., Kuntzemüller, H., Dhez, P., Wuilleumier, F. J. and Källne E., Phys. Rev. A 13 (1976) 1748-1755.

[4] Holland D. M. P., Codling K. and Marr G. V., J. Phys. B 12 (1979) 2465-2484.

[5] Holland D. M. P. and Codling K., J. Phys. B 13 (1980) L745-748; ibid. L293-298.

[6] Holland D. M. P. and Codling K., J. Phys. B 14 (1981) L359-364; ibid. 2345-2351.

[7] Lewandowski B., Ganz J., Hotop H. and Ruf M.-W., J. Phys. B 14 (1981) L803-809.

[8] Holland D. M. P. , Codling K and West J. B., J. Phys. B 15 (1982) 1473-1476.

[9] Chang T. N. and Poe R. T., Phys. Rev. A 12 (1975) 1432-1439.

[10] Carter S. L. and Kelly H. P., Phys. Rev. A 24 (1981) 170-176.

[11] Wuilleumier F. J., Ann. Phys. 4 (1982) 231-245.

[12] Schmidt V., X-Ray and Inner-Shell Processes, eds. T. A. Carlson, M. O. Krause and S. T. Manson, AIP Conf. Proc. N 215 (American Institute of Physics, New York, 1990) pp. 559-581.

[13] Lablanquie P., Electronic and Atomic Collisions, eds. W. R. McGillivray, I. E. McCarthy and M. C. Standage (Adam-Hilger, New York, 1992) pp. 507-516.

[14] Schmidt V. Rep. Prog. Phys. 55 (1992) 1483-1659.

[15] Lablanquie P., Eland J. H. D. , Nenner I., Morin P., Delwiche J. and Hubin-Franskin M., Phys. Rev. Lett. 58 (1987) 992-995.

[16] Kossman H., Schmidt V. and Andersen T., Phys. Rev. Lett. 60 (1988) 1266-1269.

[17] Lablanquie P., Ito K., Morin P., Nenner I. and Eland J. H. D., Z. Phys. D16 (1990) 77-79.

[18] Hall R. I., Avaldi L., Dawber G., Zubek M., Ellis K. and King G. C., J. Phys. B 24 (1991) 115-125.

[19] Wehlitz R., Heiser F., Hemmers O., Langer B., Menzel A. and Becker U., Phys. Rev. Lett. 67 (1991) 3764-3767.

[20] Krässig B. and Schmidt V., J. Phys. B 25 (1992) L327-333.

[21] Hall R. I., Dawber G., McConkey A., McDonald M. A. and King G. C., Z. Phys. D 23 (1992) 377 388.

[22] Hall R. I., McConkey A., Ellis K., Dawber G., MacDonald M. A. and King G. C., J. Phys. B 25 (1992) 799-810.

[23] Hall R. I., McConkey A., Avaldi L., Ellis K., McDonald M. A., Dawber G. and King G. C., J. Phys. B 25 (1992) 1195-1207. 
[24] Levin J. C., Lindle D. W., Keller N., Miller R. D., Azuma Y., Berrah Mansour N., Berry H. G. and Sellin I. A., Phys. Rev. Lett. 67 (1991) 968-971.

[25] Levin J. C., Sellin I. A., Johnson B. M., Lindle D. W., Miller R. D., Berrah N., Azuma Y., Berry H. G. and Lee D. H., Phys. Rev. A 47 (1993) R16-19.

[26] Berrah N., Heiser F., Wehlitz R., Levin J., Whitfield S. B., Viefhaus J., Sellin I. A. and Becker U., Phys. Rev. A 48 (1993) R1733-1736.

[27] Samson J. A. R., Bartlett R. J. and He Z. X. Phys. Rev. 46 (1992) 7277-7280 and rerences therein..

[28] Mazeau J., Selles P., Waymel D. and Huetz A., Phys. Rev. Lett. 67 (1991) 820-823.

[29] Schwarzkopf O., Krässig B., Elmiger J. and Schmidt V., Phys. Rev. Lett. 70 (1993) 3008-3011.

[30] Andersson L. R. and Burgdörfer J., Phys. Rev. Lett. 71 (1993) 50-53.

[31] Samson J. A. R., Greene C. H. and Bartlett R. J., Phys. Rev. Lett. 71 (1993) 201.

[32] Liu Z. W. and Liu J. C., Bull. Amer. Phys. Soc. 38 (1993) 1150.

[33] Von Raven E., Meyer M., Pahler M. and Sonntag B., J. Electr. Spectr. Rel. Phen. 52 (1990) 677-688.

[34] Krause M. O., Vestal M. L., Johnston W. M. and Carlson T. A., Phys. Rev. 133 (1964) A385-390.

[35] Carlson T. A. and Krause M. O., Phys. Rev. Lett. 14 (1965) 390-392.

[36] Carlson T. A. and Krause M. O., Phys. Rev. Lett. 17 (1966) 1079-1083.

[37] Mukoyama T., Tonuma T., Yagishita A., Shibata H., Koizumi T., Matsuo T., Shima K. and Tawara J., J. Phys. B 20 (1987) 4453-4460.

[38] Lindle D. W., Heimann P. A., Ferrett T. A., Piancastelli M. N. and Shirley D. A., Phys. Rev. A 35 (1987) 4605-4610.

[39] Heimann P. A., Lindle D. W., Ferrett T. A., Liu S. H., Medhurst L. J., Piancastelli M. N., Shirley D. A., Becker U., Kerkhoff H. G., Langer B., Szostak D. and Wehlitz R., J. Phys. B 20 (1987) 5005-5022.

[40] Carlson T. A., Mullins D. R., Beall C. E., Yates B. W., Taylor J. W., Lindle D. W.and Grimm F. A., Phys. Rev. A 39 (1989) 1170-1185.

[41] Hayaishi T., Murakami E., Yagishita A. Y., Koike F., Morioka Y. and Hansen J. E. J. Phys. B 21 (1988) 3203-3209.

[42] Aksela H., Aksela S., Pulkkinen H. and Yagishita A., Phys. Rev. A 40 (1989) 6275-6279.

[43] Becker U., Prescher T., Schmidt E., Sonntag B. and Wetzel H.-E., Phys. Rev. A 33 (1989) 38913899.

[44] Becker U., Szostak D., Kupsch M., Kerkhoff H. G., Langerand B. and Wehlitz R., J. Phys. B 22 (1989) 749-762.

[45] Aksela H., Aksela S., Bancroft, G. M., Tan K. H. and Pulkkinen H., Phys. Rev. A 33 (1989) 38673884 .

[46] Kämmerling B., Krässig B. and Schmidt V., J. Phys. B 23 (1990) 4487-4493.

[47] Hayaishi T., Yagishita A. Y., Murakami E., Shigemasa E., Morioka Y. and Sasaki T. J. Phys. B 23 (1990) 1633-1639.

[48] Hayaishi T., Yagishita A. Y., Shigemasa E., Murakami E. and Morioka Y., J. Phys. B 23 (1990) 4431-4439.

[49] Lablanquie P. and Morin P. J. Phys. B 24 (1991) 4349-4362.

[50] Hayaishi T., Murakami E., Morioka Y., Aksela H., Aksela S., Shigemasa E. and Yagishita A. Y., Phys. Rev. A 44 (1991) 2771-2774.

[51] Ueda K., Shigemasa E., Sato Y., Yagishita A. Y., Ukai M., Maezawa H., Hayaishi T. and Sasaki T. J. Phys. B 24 (1991) 605-613.

[52] Sato Y., Hayaishi T., Itikawa Y., Itoh Y., Murakami J., Nagata T., Sasaki T., Sonntag B., Yagishita A. and Yoshino M., J. Phys. B. 18 (1985) 225-231.

[53] Nagata T., West J. B., Hayaishi T., Itikawa Y., Itoh Y., Koizumi T., Murakami J., Sato Y., Shibata H., Yagisgita A. and Yoshino M., J. Phys. B 19 (1986) 1281-1290.

[54] Koizumi T., Hayaishi T., Itikawa Y., Nagata T., Sato Y. and Yagishita A., J. Phys. B 20 (1987) 53935401 .

[55] Yagishita A., Aksela S., Prescher T., Meyer M., Richter M., von Raven E. and Sonntag B., J. Phys. B 21 (1988) 945-953. 
[56] Nagata T., Itoh Y., Hayaishi T., Itikawa Y., Koizumi T., Matsuo T., Sata Y., Shigemasa H., Yagishita A. and YoshinoY., J. Phys. B 22 (1989) 3865-3880.

[57] Dzionk C., Fiedler W., von Lucke M. and Zimmermann P., Phys. Rev. Lett. 62 (1989) 878-880.

[58] Adam M. Y., Hellner L., Dujardin G., Svensson A., Martin P. and Combet Farnoux F., J. Phys. B 22 (1989) 2141-2150.

[59] Combet Farnoux F., Dujardin G., Hellner L. and Adam M. Y., X-Ray and Inner-Shell Processes, eds. T. A. Carlson, M. O. Krause and S. T. Manson, AIP Conf. Proc. N 215 (American Institute of Physics, New York, 1990) pp. 281-291.

[60] Koizumi T., Hayaishi T., Itikawa Y., Itoh Y., Matsuo T., Nagata T., Sato Y., Shigemasa E., Yagishita A. and Yoshino M., J. Phys. B 23 (1990) 403-415.

[61] Matsuo T., Hayaishi T., Itoh Y., Koizumi T., Nagata T., Sato Y., Shigemasa E., Yagishita A., Yoshino M. and Itikawa Y., J. Phys. B 25 (1992) 121-133.

[62] Sonntag B. and Zimmermann P., Rep. Prog. Phys. 55 (1992) 911.

[63] Becker U. and Shirley D. A., Physica Scripta T31 (1990) 56-66.

[64] Richter M., Bizau J.-M., Cubaynes D., Menzel T., Wuilleumier F. J. and Carré B., Europhys. Lett. 12 (1990) 35-40.

[65] Wolff H. W., Radler K., Sonntag B. and Haensel R., Z. Physik 257 (1972) 353- 368.

[66] Cubaynes D., Bizau J.-M., Richter M. and Wuilleumier F. J., Europhys. Lett. 14 (1991) 747-753.

[67] Fano U., Phys. Rev. 124 (1961) 1866-1878.

[68] Fano U. and Cooper J. W., Phys. Rev. 137 (1965) A1364-1379.

[69] Starace A. F., Phys. Rev. A 16 (1977) 231-242.

[70] Sladeczek, Selbman K.-H., Richter M., Zimmermann P., Rouvellou B., Journel L., Bizau J.-M. and Wuilleumier F. J., to be published.

[71] Codling K., Hamley J. R. and West J. B., J. Phys. B 10 (1977) 2797-2807.

[72] Breuckmann E., Breuckmann B., Mehlhorn W. and Schmitz. W., J. Phys. B 10 (1977) 3135-3150.

[73] Codling K., Madden R. P. and Ederer D. L., Phys. Rev. 155 (1967) 26-37.

[74] Madden R. P. and Codling K., Phys. Rev. Lett. 10 (1963) 516-518.

[75] Codling K., Synchrotron Radiation: Techniques and Applications, ed. C. Kunz (Springer-Verlag, Berlin, 1979) pp. 231-268 and references therein.

[76] Kobrin P. H., Becker U., Southworth S., Truesdale C. M., Lindle D. W. and Shirley D. A., Phys. Rev. A 26 (1982) 842-856.

[77] Lindle D. W., Ferrett T. A., Heimann P. A. and Shirley D. A., Phys. Rev. A 36 (1987) 2112-2119.

[78] Kossmann H., Krässig B. and Schmidt V., J. Phys. B 21 (1988) 1489-1497.

[79] Becker U., Wehlitz R., Hemmers O., Langer B. and Menzel A. Phys. Rev. Lett.63 (1989) 1054-57.

[80] Svensson S., Martensson N. and Gelius U., Phys. Rev. Lett. 58 (1987) 2639-2641.

[81] Svensson S., Stranges S. and Adam M. Y., Phys. Rev. A 48 (1993) 3051-3055. 